RESENHA

\title{
A lógica do ser de Hegel
}

*João Alberto Wohlfart

\section{RESENHA DE:}

HEGEL, G.W. F. Ciência da lógica: 1. A doutrina do ser. Tradução de Christian Iber, Marloren L. de Miranda, Federico Orsini e Agemir Bavaresco (Coordenador). Petrópolis, RJ: Vozes; Bragança Paulista, SP: Ed. Universitária São Francisco, 2016. 464 p. ISBN 9788532653086.

T emos em mãos a tradução para o português do primeiro livro da Ciência da Lógica, intitulado por Hegel de "Lógica do ser". Resultante de um trabalho em equipe realizado por Christian Iber, Marloren L. de Miranda, Federico Orsini, Agemir Bavaresco, Michela Bordignon, Tomas Farcic e Karl Heinz Efken. Do trabalho coordenado por esta equipe saiu a bela tradução coroada com a editoração e publicação realizada no melhor estilo pela Editora Vozes.

Com a tradução, os falantes da língua portuguesa têm em mãos uma obra filosófica estruturante do pensamento moderno e uma das mais importantes da História da Filosofia. Temos agora e nossas mãos, em língua portuguesa, uma obra de difícil acesso do pensamento hegeliano e que um filósofo de língua portuguesa leria com muita dificuldade. A tradução, ora disponibilizada, tenta conciliar a difícil linguagem hegeliana escrita em alemão com a fluência típica do nosso português, permitindo uma compreensão mais ou menos fácil por parte do falante da língua portuguesa.

A tradução ora apresentada é o primeiro livro da Ciência da Lógica hegeliana, intitulado "A doutrina do ser" e conhecida como lógica objetiva. Hegel oferece uma orientação metodológica radicalmente diferente das empregadas na pesquisa filosófica, o que expressa o seu

* Doutor em Filosofia pela PUCRS. Professor titular de Filosofia no Instituto Superior de Filosofia Berthier.<joao@fabemarau.edu.br>. 
caráter altamente inovador e revolucionário. Hegel não começa por algo já determinado, por um ponto de partida fixo, por uma substância definida ou por um absoluto originário, mas parte do ser como indeterminado, vazio e abstrato. Não se trata do ser como conceito mais rico, como na tradição ontológica clássica, mas como começo mais pobre, sem nenhuma pressuposição de algo determinado.

Como no começo da Lógica não há nenhuma pressuposição, nenhum conteúdo, a sua determinação primeira é o nada. Contrariamente à ontologia clássica, para Hegel, ser e nada não se excluem como a absoluta afirmação e a absoluta negação, mas se integram em todo o curso de desenvolvimento racional. Como o ser é totalmente vazio, e como se identifica radicalmente com o nada, a primeira determinação da Ciência da Lógica é o devir. Esta categoria concentra em si mesma a universalidade vazia do ser, porque simplesmente é, e o nada, pois o devir compreende o já realizado e o ainda não realizado, na condição do devir.

$\mathrm{Na}$ Lógica do ser, Hegel começa exatamente pelos primórdios da história da filosofia, por Parmênides e por Heráclito. Nesta avaliação, nem tudo é ser e nem tudo é nada, nem tudo é movimento, nem tudo é repouso, mas uma combinação entre estes dois elementos. Estabelecendo o começo pelo mais indeterminado e mais vazio, a Lógica empreende um caminho de desenvolvimento permanente no qual se misturam o ser e o repouso, de Parmênides, e o nada e o movimento, de Heráclito. Esta característica metodológica fundante proporciona ao livro da Lógica do ser e a toda a filosofia hegeliana um caráter revolucionário e inovador do pensamento. Com este começo para a filosofia, Hegel questiona radicalmente as outras formas de fazer filosofia na tradição filosófica e adota uma metodologia jamais antes concebida pela filosofia.

A leitura da Lógica do ser expressa imediatamente uma dupla função filosófica. Na condição de pensamento filosófico fundamental, a Lógica do ser é uma lógica, no sentido de que expõe uma série de categorias racionais e representa uma estrutura categorial completa através da qual o pensamento se articula logicamente. Trata-se de uma lógica segundo a qual categorias contrárias, historicamente sempre antinômicas e irredutíveis, são equilibradamente integradas em síntese, tais como ser e nada, qualidade e quantidade etc. Mas a Lógica do ser não se reduz a uma lógica, e nisto está o seu caráter revolucionário, mas ela também assume a função fundamental de uma metafísica. E com este começo, o que vale para todo o pensamento hegeliano, as leis do pensamento são também as leis do ser e vice-versa. Para Hegel, a realidade não é uma objetividade imediata, uma mera contingencialidade exterior, mas impregnada pela racionalidade e se articula racionalmente. Do ponto de vista metafísico, a realidade é pensada a partir da significatividade das categorias 
e estruturas categoriais da Ciência da Lógica, o que proporciona às diferentes estruturas do real outro estatuto de racionalidade.

Com a Lógica do ser na dianteira, a filosofia hegeliana caminha nesta dupla perspectiva de afirmação e de integração de lógica e de metafísica. Estas duas disciplinas filosóficas fundamentais não ocupam lugares fixos e estanques ao longo da obra hegeliana, mas se interpenetram universalmente, especialmente na passagem da Ciência da Lógica na Filosofia do Real, na qual a realidade é logicamente articulada e pensada. A própria estruturação da Lógica do ser, nas suas categorias estruturantes, são formas de compreensão racional da própria realidade. Nesta perspectiva, a subjetividade da lógica se transforma na objetividade do real, enquanto a realidade exterior é subjetivada pelo pensamento, e por isto metafisicamente fundamentada.

Hegel estrutura a Lógica do ser em qualidade, quantidade e medida. Contrariamente à metafísica clássica, que começa com determinações quantitativas, Hegel começa com a pura qualidade do ser que simplesmente é, sem ulteriores determinações. Do ponto de vista qualitativo, o ser é negativamente determinado como nada, como absolutamente vazio de determinações iniciais. Novamente, começando com a qualidade pura, Hegel não procede como no pensamento clássico e não estabelece um conjunto de qualidades fundamentais que seriam o indicativo da identidade de algo. Pois, em nenhum lugar da Lógica e de seu pensamento, tem validade a fórmula clássica da identidade segundo a qual $\mathrm{A}=\mathrm{A}$. Na sequência, Hegel desenvolve uma reflexão sobre a quantidade, não como um procedimento isolado da qualidade, mas desta que se determina quantitativamente. A Lógica do ser conclui com a noção de medida na qual o filósofo concilia a qualidade e a quantidade, como uma espécie da quantidade qualificada.

Hegel, ao formular o conceito metafísico de qualidade, não o faz na perspectiva da identificação das qualidades fundamentais de um objeto que o diferenciam qualitativamente de outros e estabelece a radical diferença e incomunicabilidade. A referência fundamental na abordagem da qualidade por parte de Hegel é a inclusão da diferença e da contradição como constitutivas do ser. Faz parte de qualquer algo conter em seu interior a sua própria negação e contradição, superando radicalmente a noção das qualidades imediatas de algo como metafisicamente determinadas. Nesta dinâmica, é intrinsecamente um componente dinamizador da qualidade que algo se torna seu outro, e que o outro se torna outro, e qualquer algo na relação com o outro se transforma num outro em relação a este outro. Para Hegel, "algo tem também uma determinação ou circunstância em si (aqui o acento cai sobre em) ou nele, na medida em que essa circunstância é externa nele, um ser para 
outro" (p. 125). Nesta formulação hegeliana, não são as qualidades fixas características de algo que vão determiná-lo, mas a sua relação com o outro na contradição de si mesmo. Algo somente será ele mesmo quando passa pelo outro e se torna outro, e este algo, ao passar pelo outro, se torna outro do outro, e somente assim resgata a sua verdade.

Este argumento é decisivo para formulação hegeliana do conceito de infinitude. No início de sua Lógica, o filósofo já quebra com o que podemos denominar de autonomia e isolamento metafísico dos seres. Nesta concepção, quanto maior a identidade, menos intensa será a dependência relacional de algo em relação a outro alto. Pelo caminho hegeliano, algo se diferencia e passa pelo outro de si, este outro de si passa pelo outro do outro, de tal modo que todos os seres passam pela sua diferença. Este argumento supera a condição da finitude e da parcialidade isoladas nelas mesmas, para o estabelecimento da qualidade fundamental segundo a qual todas as coisas são elas mesmas pelas outras, o que conduz ao conceito de infinitude.

Uma das significativas reflexões oferecidas por Hegel neste começo da Lógica do ser é a dialética da finitude e da infinitude. Contrariamente ao caráter transcendente da infinitude enquanto sobreposta ao finito e determinado, Hegel propõe um conceito de infinitude que inclui em seu interior o conceito de finitude. Se a finitude é rebaixada em relação à infinitude, esta encontrará na finitude o seu limite, razão pela qual também permanece na finitude. A infinitude contraposta à finitude como dois patamares excludentes transforma aquela numa condição finita e abstrata. Na exposição hegeliana realizada na Lógica do ser, a infinitude se torna verdadeira se ela for preenchida pela finitude, enquanto esta recebe outro estatuto de racionalidade enquanto momento da infinitude. $\mathrm{Na}$ verdade, finitude e infinitude formam um círculo dialético no qual a finitude se amplia e se infinitiza, na multiplicidade de elementos finitos que se perpassam e se elevam ao infinito. Para Hegel, "no perecer o finito não pereceu; ele se tornou, inicialmente, apenas um outro finito, que, contudo, é igualmente o perecer como passar para um outro finito e assim por diante, por assim dizer, para o infinito" (p. 141). Nesta lógica, a infinitude é resultado da negação da finitude, da infinitização da finitude, e a infinitude reconduzida à finitude como finitização da infinitude, o que estabelece uma essencial relacionalidade entre finitude e infinitude.

A segunda parte da Lógica do ser Hegel dedica à quantidade. De forma aparente e imediata, a quantidade se contrapõe à qualidade como conceitos excludentes, na medida em que a qualidade trata da grandeza intensiva e a quantidade trata da grandeza extensiva, exterior e imediata. Nesta acepção, a quantidade fica excluída da determinação da qualidade de algo. Mas a exposição hegeliana vai numa direção diferente, na 
medida em que a qualidade e a quantidade se integram reciprocamente, pois quanto maior a qualidade, maior a quantidade, e quanto maior a quantidade, maior a qualidade. As duas dimensões estão de tal maneira integradas que uma muda a partir de outra, pois a mudança quantitativa representa uma mudança qualitativa e vice-versa. Quando um pobre, por exemplo, é sorteado numa aposta lotérica e ganha milhões, aumenta quantitativamente o volume de dinheiro e se transforma qualitativamente de pobre em rico.

Hegel aponta exemplos que demonstram a implicação recíproca entre a qualidade e a quantidade, especialmente na recíproca e proporcional intensificação de um em relação ao outro. Assim, quando a água é submetida a um aquecimento ela se transforma qualitativamente em estado gasoso; e quando a mesma água é submetida a um esfriamento ela se transforma qualitativamente em gelo. Hegel nos mostra no início da sua Lógica que qualidade e quantidade não são determinações conceituais contrapostas e exclusivas, mas uma se constitui através da outra e uma se transforma na outra. Com esta inspiração fundamental, em todo o sistema filosófico hegeliano o processo de qualificação implica num dinamismo de quantificação, e todo o processo de quantificação qualifica o processo.

Ao formular o significado da quantidade, Hegel não está preocupado com a pura quantidade espacial, como o tamanho de uma cancha de futebol, a extensão de uma gleba de terra, a extensão territorial de um de um espaço geográfico. Na sua exposição, qualidade e quantidade estão implicadas, respectivamente, como a interioridade e a exterioridade. A qualidade aparece como a faceta interiorizada de algo, enquanto a quantidade é configurada como a faceta exteriorizada da mesma realidade. Hegel dirime a antinomia clássica entre qualidade e quantidade ao expor estas categorias na mesma intensidade integradora. Entre estes dois capítulos da Lógica do ser há uma razão de aproximação e integração destas duas categorias fundantes. Na qualidade, conforme vimos, algo não se caracteriza por suas qualidades fixas e definidas, mas passa pela negação e pela diferença. Nisto se estabelece uma diferenciação universal no sentido de que todas as coisas se afirmam a si mesmas na negação, numa mistura de tudo com tudo e numa continuidade fundamental entre as coisas. A faceta exteriorizada desta configuração da qualidade é a quantidade pura.

Para uma compreensão mais aprofundada da quantidade, além da quantidade contínua e descontínua, Hegel fala de quantidade intensiva e quantidade extensiva. Para Hegel, "grandeza extensiva e intensiva são, portanto, uma e a mesma determinidade do quantum; elas são diferentes apenas pelo fato de que uma tem o valor numérico como dentro de si, a 
outra tem o mesmo, o valor numérico, como fora dela" (p. 235). O puro número nada mais representa que quantidade extensiva. A multiplicidade de coisas extensivas medidas em números pode ser transformada em quantidade intensiva, pois as coisas em números extensivos são integradas numa referência comum. A infinitude quantitativa significa que um determinado número e uma determinada referência de quantidade podem ser superadas por outra quantidade mais extensa, assim ao infinito. Uma quantidade superada por outra quantidade resulta num progresso ao infinito. Mas esta linearidade é superada na esfera da relação quantitativa na qual dois opostos se integram dialeticamente. Para Hegel, o progresso quantitativo ao infinito é algo vazio, compensado pela integração de potências opostas, tais como a transcendência e imanência, saber quantitativo e integrador. Nesta lógica, quanto maior e mais extensa a transcendência, mais intensa será a imanência e a interioridade, e quanto mais extensa a quantidade de conhecimentos, mais intensa é a sua organicidade e sistematicidade.

Hegel fala em vários níveis e graus de quantidade. Uma delas é a quantidade absoluta, a quantidade ilimitada, a quantidade indeterminada, a quantidade não ultrapassada por nenhuma realidade mais abrangente e extensa. Esta quantidade representa a extensão absoluta, como pura e simplesmente quantitativa. Esta pura quantidade, como uma extensão continuada e ilimitada, não é oposta à qualidade na condição de pura indeterminação. A quantidade absoluta não é antinômica às qualidades internas desta pura indeterminação universal que a preenchem internamente, de forma que não é contraposta à elementaridade das coisas particulares. Dentro da pura quantidade, Hegel também fala do quantum, uma quantidade determinada. Para que uma determinada qualidade seja justificada, ou para que uma coisa seja determinada, a sua expressão quantitativa deve ser limitada e diferenciada das outras.

A terceira categoria fundante da Lógica do ser é a medida. Isto significa dizer, em outras palavras, que nenhuma coisa é autossuficiente nela mesma, mas para possuir qualquer referência de racionalidade deve remeter constitutivamente a algo diferente que Hegel estabelece na medida. A medida especifica as coisas. Ao longo da exposição da terceira parte da parte da Lógica do ser, várias referências de medida são estabelecidas, destacadamente a regra e a medida real. A regra, por exemplo, regula um jogo e as relações sociais para que as mesmas não se transformem numa violência generalizada. Hegel fala também da combinação entre duas medidas autossubsistentes, tais como, por exemplo, entre as moedas de dois países vizinhos, cuja combinação regula os preços das mercadorias dos referidos países. Mas a medida evolui para uma série de relações de medida, quando se encaminha para 
um sistema de relações de medida sempre superável pela desmedida, categoria conclusiva da Lógica do ser.

Hegel estabelece a síntese entre qualidade e quantidade na medida como quantidade qualificada. Não se trata, portanto, de uma pura quantidade exterior e vazia, como o puro espaço, o puro tempo e o puro número, mas se trata de uma quantidade qualificada e densificada na condição de real e existente. Aqui advém uma primeira proposição que, no fio condutor da Ciência da Lógica e da Enciclopédia das Ciências Filosóficas, segundo a qual o Absoluto alcança tal nível de universalidade e determinação. No caso da medida, Deus aparece como a medida de todas as coisas. Mas o argumento principal do terceiro capítulo da Lógica do ser é a transformação da qualidade em quantidade e da quantidade em qualidade na unidade da medida. Porém, este círculo de transformação de um no outro se rompe sucessivamente para estabelecer uma nova circularidade integradora entre qualidade e quantidade na medida. Com esta circularidade aberta e desenvolvimento ao infinito, a medida é permanentemente quebrada e ela se transforma em desmedida como resultado da Lógica do ser. Para Hegel, "o sem medida abstrato é o quantum em geral como sem determinação dentro de si e como determinidade apenas indiferente, pela qual a medida não é alterada" (p. 400). Nesta lógica, todos os padrões de medida são superados e tudo se transforma numa desmedida universal. Esta é uma expressão de que na Lógica do ser tudo é indeterminado, imediato, pois as coisas não estão determinadas em si mesmas, nem umas em relação às outras.

A medida conclui com a indiferença absoluta, pois na Lógica do ser tudo mergulha numa indiferença generalizada. Dentro do ser tudo está imerso de forma quantitativa, mas sem nenhuma diferenciação qualitativa. Neste nível, como no ser não há diferenciação qualitativa entre as coisas, porém a continuidade qualitativa resulta na indiferenciação quantitativa. "A determinidade, dessa maneira, está posta no substrato apenas ainda como um diferenciar vazio. Mas, precisamente esse diferenciar vazio é a própria indiferença como resultado" (p. 403). Nesta acepção, a qualidade e a quantidade caem num vazio total, pois a absoluta indiferença representa a exteriorização da qualidade na absoluta indeterminação. Se isto fosse traduzido para exemplos concretos, haveria uma única matéria indiferenciada, um único pensamento, uma única e contínua realidade sem diferenciação interna ou externa. Nesta lógica, a multiplicidade qualitativa fica diluída numa mistura generalizada, resultante na igualdade da indiferença absoluta. A conclusão da Lógica do ser coincide com a dissolução total das determinidades que se fundem num único éter universal e indiferenciado. 
A Lógica do ser se revela como insuficiente para resolver o problema básico da determinação das coisas. Como a sua verdade é a indeterminação e indiferenciação absoluta, dentro deste universo não é possível a determinidade de algo. A passagem da Lógica do ser na Lógica da essência caracteriza o caminho do vazio exterior e indiferença generalizada para a interioridade da reflexão e do universo da essência propriamente dito. Para Hegel, "a indiferença absoluta é a última determinação do ser, antes de ele se tornar essência; mas a indiferença não a alcança. Ela se mostra como tal que pertence ainda à esfera do ser, visto que ela ainda, determinada como indiferente, tem nela a diferença como externa, como quantitativa" (p. 412). Se a conclusão da Lógica do ser é marcada pela desmedida, a Lógica da essência será o momento estruturante da afirmação do que a esfera do ser era incapaz em si mesma. O sistema da essência estabelece um universo de coisas determinadas, cada uma das quais insuficiente em si mesma enquanto separadas das outras. Hegel constrói um conceito de essência diferente daquele da tradição metafísica, mas a profunda crítica hegeliana estabelece como critério fundamental para a determinação de um sujeito a reflexão sobre si mesmo na mesma medida da reflexão sobre outro, quando tudo se transforma num qualificado sistema de relações no qual tudo está relacionado a tudo e todas as coisas integram um sistema de relações. Neste círculo, todas as coisas se determinam numa determinação específica, enquanto esta se estende para todo o sistema no qual e com o qual se relaciona de forma constitutiva.

Com a publicação da Lógica do ser em Português e com esta bela edição em nossas mãos, é possível afirmar com maior propriedade o caráter revolucionário desta obra para a Filosofia. É possível dizer sem receio que, com a Lógica do ser, Hegel declara insuficientes, defeituosas e unilaterais todas as filosofias anteriores e inaugura um jeito completamente novo de pensar a filosofia. Não se trata de nenhuma forma de dogmatismo filosófico que estabelece um ponto de partida já definido e inquestionável, superado por Hegel pela radical indeterminação do ser. A partir desta posição, é justificada a lógica interna da Ciência da Lógica e de todo o sistema filosófico, que caracteriza a constante passagem da indeterminação na determinação, da universalidade abstrata na universalidade concreta, num processo de diferenciação e de qualificação interna em níveis de totalidade cada vez mais amplos e complexos. Nesta lógica, não é apenas efetivado o que é racionalmente pressuposto, mas caracteriza uma diferenciação qualitativa.

A Lógica do ser caracteriza um núcleo lógico-ontológico fundamental da filosofia hegeliana. Mesmo que se dê mais valor à Lógica da essência ou à Lógica do conceito, estas duas esferas lógico-ontológicas constituem 
desdobramentos do primeiro livro da Ciência da Lógica. Conforme já afirmamos, este livro já significa uma radical reviravolta, reestruturação e ressignificação da filosofia em geral, de forma que pouca coisa da tradição filosófica sobra sem a presença desse novo olhar filosófico. Por outro lado, Hegel já prepara neste livro as condições racionais fundamentais para um novo desenvolvimento metódico da filosofia enquanto exposição do sistema filosófico nos momentos fundamentais de passagem na Lógica da essência e na Lógica do conceito. Não se trata mais de uma ontologia tradicional como metafísica da essência estática contraposta aos acidentes, mas de um núcleo lógico-ontológico que integra à qualidade ontológica a quantidade a e a espacialidade enquanto formas de exteriorização qualitativa. Neste sentido, a indeterminação generalizada e absoluta que o ser conclui na desmedida pode significar uma dissolução generalizada das estruturas fixas de racionalidade da História da Filosofia ocidental e um começo de reformulação generalizada da concepção, do método e da estrutura do pensamento filosófico. Daqui procede a noção de absoluto como indeterminação do ser e as suas múltiplas formas de determinação e autodeterminação ao longo do sistema da Enciclopédia das Ciências Filosóficas.

\section{Endereço postal:}

Instituto Superior de Filosofia Berthier - IFIBE

Rua Senador Pinheiro, 350 - Vila Rodrigues

99070-220, Passo Fundo, RS, Brasil

Data de recebimento: 08-09-2017

Data de aceite: 19-09-2017 